\title{
Investigation of the Risk of Daily Officer Work Posture Based on Rapid Upper Limb Assessment (Rula) Method
}

\author{
Sri Widiyawati*, Rio Prasetyo Lukodono, Astuteryanti Tri Lustyana, Izzaudin Afif Pradana \\ Department of Industrial Engineering, Brawijaya University, Indonesia
}

Received July 25, 2019; Revised December 20, 2019; Accepted December 23, 2019

Copyright $\subseteq 2020$ by authors, all rights reserved. Authors agree that this article remains permanently open access under the terms of the Creative Commons Attribution License 4.0 International License

\begin{abstract}
Work activities in the office are generally static and take a long period of time. This activity is carried out with awkward postures that result in fatigue and injuries. The study is conducted in one of the business entities providing services construction and management of network infrastructure at the Division of Process Aligning Service Comply in January 2019. These activities are reflected in the conditions of work posture for bending, the use of maximum range and uncomfortable position of certain body parts, and will have an impact on decreasing productivity of workers. Therefore, an analysis was carried out to evaluate the posture of employees in order to find the potential problem of the work posture used. The RULA method can be used to evaluate musculoskeletal load in a job where a person has the risk of the upper-body activity. The sample used in this study was workers who work in a sitting position with their activities using a computer. Based on the analysis, it is known that worker activity gets a score that indicates that the workstation requires a change.
\end{abstract}

Keywords Static Posture, Awkward Posture, Fatigue, RULA

\section{Introduction}

In the manufacturing and service industries, there are many activities that involve interactions between humans and machines. The interaction between these two things can be found in many production processes, namely in processing inputs to produce output. But in fact, the humans and the work facilities not always synchronous, so the design need to adjust the humans ability and posture [1]. This is not by following the term fit the machine to the man, which results in various complaints by workers such as easy fatigue and injury. Complaints and injuries experienced by workers can be seen from the level of the shoulder and neck muscle contraction is high and prolonged. Designs with extreme work postures can increase the risk of Musculoskeletal Disorders (MSDs) injuries to workers' muscle, tendon, ligament, joints, peripheral nerve, and blood vessels support, necks and shoulders $[2,3]$.

MSDs is an abnormal condition in the nerves, muscles and other supporting structures of the body [2]. The other case mentioned that bad posture especially like sitting can cause serious health problems such as heart attack, stroke, health problem and main cause of obesity $[4,5,6]$.

Ergonomics is the study of the relationship between humans and machines in a system and applies theory and data to design a system that meets human needs. Ergonomics as the study of humans as components in work systems includes physical and non-physical characteristics, as well as human limitations and abilities in designing systems that are effective, safe, healthy, comfortable, and efficient [7]. Ergonomics contributes to the improvement of work stations for service compliant workers by following the rules in ergonomics

Considering ergonomic relates to work postures can help solve problems that occur to workers and cause comfort for workers, the intended work postures include sitting, standing, and transport work postures [8]. Ergonomic considerations comprise 4 points:

1. Reducing the need of workers to work in a bent work posture with frequent or in long periods.

2. Workers should not use maximum coverage. Work posture settings, in this case, are carried out within a normal range.

3. Workers should not sit or stand while working for long periods with their head, neck, chest, or legs in a slanted work posture. If this happens continuously, then the metabolic process in the body will be disrupted due to the lack of blood supply that carries oxygen into that part of the body.

4. Operators should not be forced to work in frequency or long periods with their hands or arms in a position above the normal elbow level. When doing the process of aligning the service complies the operator is 
expected to relax so that it does not cause excessive fatigue and injury.

Common methods that are used to analyze the work postures of operators are OWAS, NIOSH, RULA, OCRA, REBA, LUBA, and EAWS [9,10,11]. RULA is a method to analyze inappropriate work postures, such as the work postures of children in school, the postures of children while using computers $[12,13,14]$. RULA has high the reliability when the analyzer is same person [14]. This method produces a value that can be used as a reference that a worker's body posture is good or not, so that it can be used as the basis for a workstation redesign. In RULA, the analyzed parts are arms, wrists, neck, and legs and produce final grades ranging from 1 (low risk) to 7 (high risk) [Stanton].

In this study, RULA method will be used to assess the risk of working postures in providing services construction and management of network infrastructure, a Telecommunication Service in Malang, East Java, Indonesia. Work activities that will be analyzed is the process of aligning Service Comply. Based on initial observation, almost all activities are still done with computer and involve less comfortable working posture. This condition often causes the workers feel some pains in the upper body parts, even those pains sometimes still remain up to several days. Therefore, the working postures in Service Comply line will be analyzed further using RULA method to know the risk level and appropriate proposed improvements can be given to reduce the risk level.

\section{Material and Method}

\subsection{Material}

Data collection was conducted in the effective working hours in Service Comply line during three month observation. Primary data were obtained by distributing Nordic Body Map questionnaires to 33 workers in divisions and 6 workers in the Service Comply line. This division is considered to be able to represent other divisions because the majority of the work is in front of the computer. The characteristics of respondent are age range $21 \pm 4$ years old and their weight with $61 \pm 11 \mathrm{Kg}$ with duration of work is 8 hours.

Nordic Body Map Questionnaire is one of the subjective measurement methods for measuring musculoskeletal complaints in workers [15]. The musculoskeletal system is a system that gives animals and humans the ability to move using the muscular and skeletal systems. The Nordic Body Map questionnaire consists of 28 questions about the motion in all parts of the body. These twenty-eight question items cover nine main body parts namely the neck, shoulders, upper back, elbows, lower back, wrists or hands, waist or buttocks, knees, heels, and feet. The Nordic Body Map Questionnaire is shown at Figure 1. 


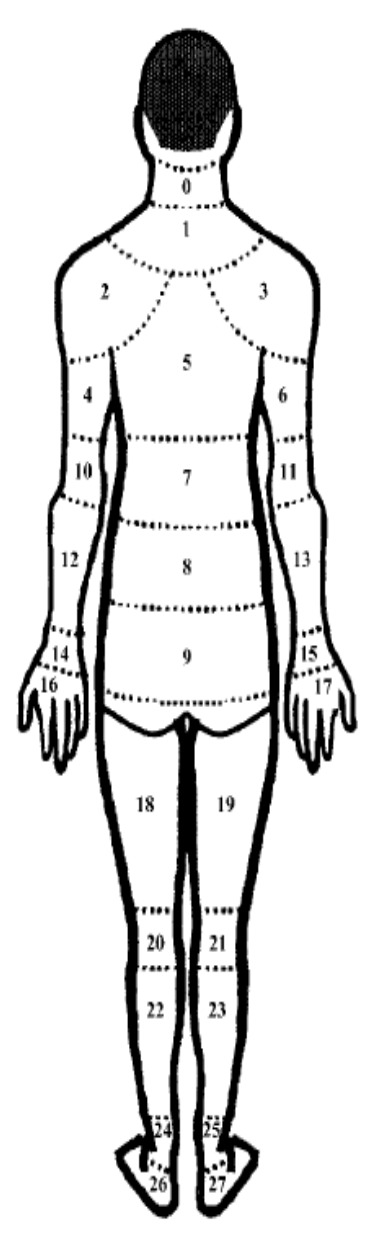

\begin{tabular}{|c|l|l|l|l|l|}
\hline No & \multicolumn{3}{|c|}{ Location } & \multicolumn{3}{|c|}{ Grade of complaints } \\
\hline 0 & Pain/stiff in the upper neck & A & B & C & D \\
\hline 1 & Pain in the lower neck & & & & \\
\hline 2 & Pain in the left shoulder & & & & \\
\hline 3 & Pain in the right shoulder & & & & \\
\hline 4 & Pain in the left upper arm & & & & \\
\hline 5 & Pain in the back & & & & \\
\hline 6 & Pain in the right upper arm & & & & \\
\hline 7 & Pain in the waist & & & & \\
\hline 8 & Pain in the buttock & & & & \\
\hline 9 & Pain in the bottom & & & & \\
\hline 10 & Pain in the left elbow & & & & \\
\hline 11 & Pain in the right elbow & & & & \\
\hline 12 & Pain in the left lower arm & & & & \\
\hline 13 & Pain in the right lower arm & & & & \\
\hline 14 & Pain in the left wrist & & & & \\
\hline 15 & Pain in the right wrist & & & & \\
\hline 16 & Pain in the left hand & & & & \\
\hline 17 & Pain in the right hand & & & & \\
\hline 18 & Pain in the left thigh & & & & \\
\hline 19 & Pain in the right thigh & & & & \\
\hline 20 & Pain in the left knee & & & & \\
\hline 21 & Pain in the right knee & & & & \\
\hline 22 & Pain in the left calf & & & & \\
\hline 23 & Pain in the right calf & & & & \\
\hline 24 & Pain in the left ankle & & & \\
\hline 25 & Pain in the right ankle & & & \\
\hline 26 & Pain in the left foot & & & \\
\hline 27 & Pain in the right foot & & & \\
\hline & & & & & \\
\hline
\end{tabular}

Figure 1. Nordic Body Map Questionnaire

\subsection{Method}

The data required for this research were work elements and awkward work postures from each of these elements. The methods of data collection were direct observation and taking picture of the work activities being performed by Service Comply worker. Direct observation was conducted to know the work elements and understand the order. Taking picture of awkward postures will be analyzed further using RULA method.

RULA is a method of calculating the musculoskeletal load rating in an occupation where a person will have the risk of loading the upper body and neck [16]. This method will provide a value that explains a job where the value reflects the state of posture, style and movement carried out. The analyzed part includes the arms, wrists, neck, and legs and provides results in the form of scores 1 (low risk) to 7 (high risk) [17]. Working posture of each element will be processed according to the steps in the RULA method as follows:

1. Assessing posture for group A (upper arm, lower arm, wrist).
2. Adding muscle use and force scores for group A.

3. Assessing posture for group B (neck, trunk, and legs).

4. Adding muscle use and force scores for group B.

5. Determining RULA grand score and action level.

\section{Result and Discussion}

\subsection{Result}

Analysis of the Service Comply operator's work postures at this telecommunications company was carried out using the Rapid Upper Body Assessment (RULA) method. To find out the first complaint that occurred. This study used the Nordic Body Map questionnaire. The Nordic Body Map questionnaire was distributed to 6 service comply workers to find out complaints that were experienced by workers. The results of the Nordic Body Map Questionnaire showed various kinds of complaints experienced by workers when aligning service comply. The most common complaints experienced by workers were: 
1. Workers felt a slight pain in the neck, and this was due to the operator being slightly bent while working.

2. Workers felt a little pain in the upper arm, and this was caused by a lot of movements that were done using the hands a lot.

3. Workers felt a little pain in the back was due to the position of the back that was not optimal.

4. Workers felt a slight pain in the waist due to improper sitting position.

5. Workers felt pain in the lower part of the waist and buttocks, caused by a hard chair. Therefore, it caused pains in the bottom of the waist and buttocks when sitting for long time.

6. Workers felt a little pain in the right wrist because during work, the wrist rotated excessively until reaching the limit of hand rotation.

7. Workers felt a little pain in the fingers because during work, multiple fingers were extensively used when typing

8. Workers felt a little pain in the thighs because the employee's most work time was in sitting position.

After knowing the complaints experienced by workers, the study was proceeded with analyzing work postures using RULA. The work posture value was taken in one cycle which was considered to have the greatest risk to the health of the worker. The assessment was carried out to find out whether the workers' posture followed the principles of ergonomics. In the collection of RULA data, sampling was done by photographing the body posture of the Department of Service Comply alignment. Assessment of posture was very important to anticipate things that could endanger workers in the long and short term. Here is a picture of the work posture and the angles formed by the upper body as the basis for filling in The RULA Scoring Sheet. Figure 2 presents the posture of the service comply aligning operator.

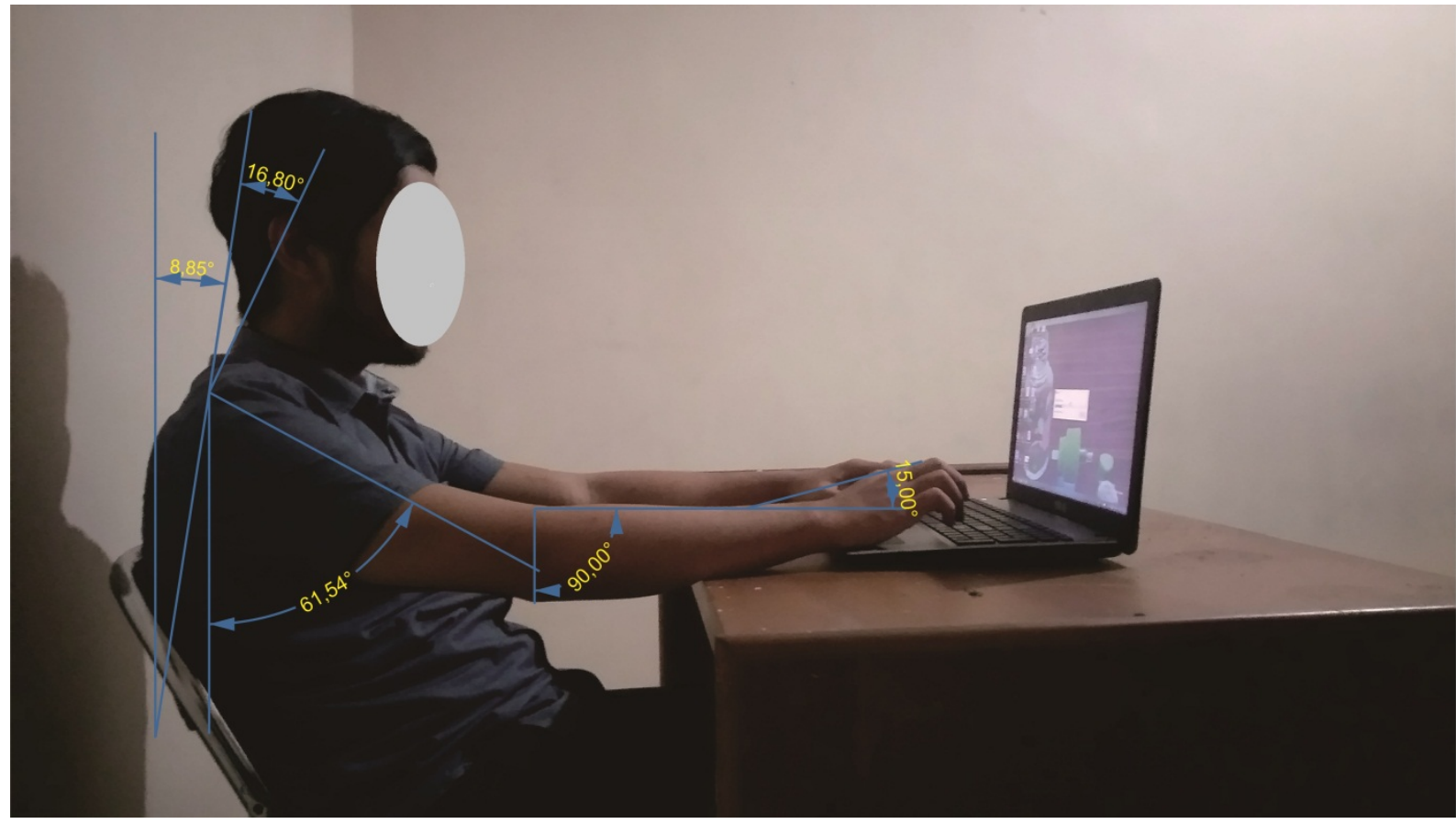

Figure 2. The posture of the Service Comply Aligning Operator 
a. Assessment of work postures for the body included in category A (Upper arm, Lower arm, Wrist)

1) Upper Arm
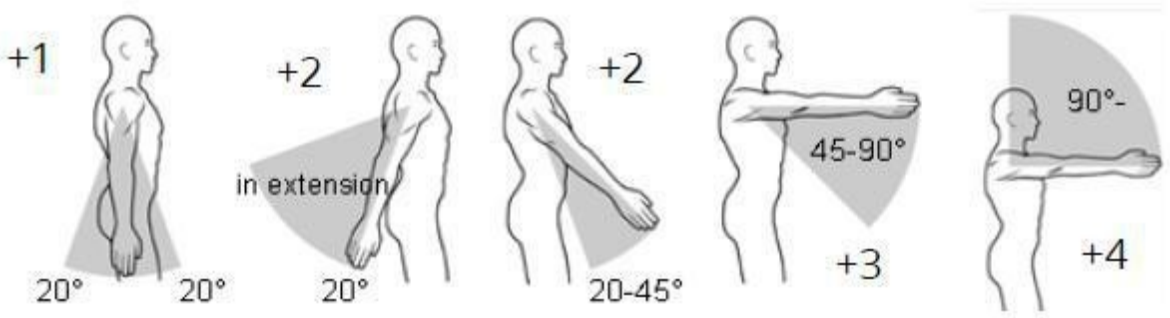

Figure 3. Upper Arm Position

Based on this work posture, it can be seen that the upper arm forms an angle of $61.54^{\circ}$. With an angle of $61.54^{\circ}$, it can be seen the upper arm score was +3 . Because in the process of aligning the service comply, the open arms were positioned to the side, the score given was +1 . Because of the process of aligning the service comply, the arms were resting on the desk/laptop, the score given was -1 . Therefore, the total value for the upper arm was $3+1-1=+3$

2) Lower Arm
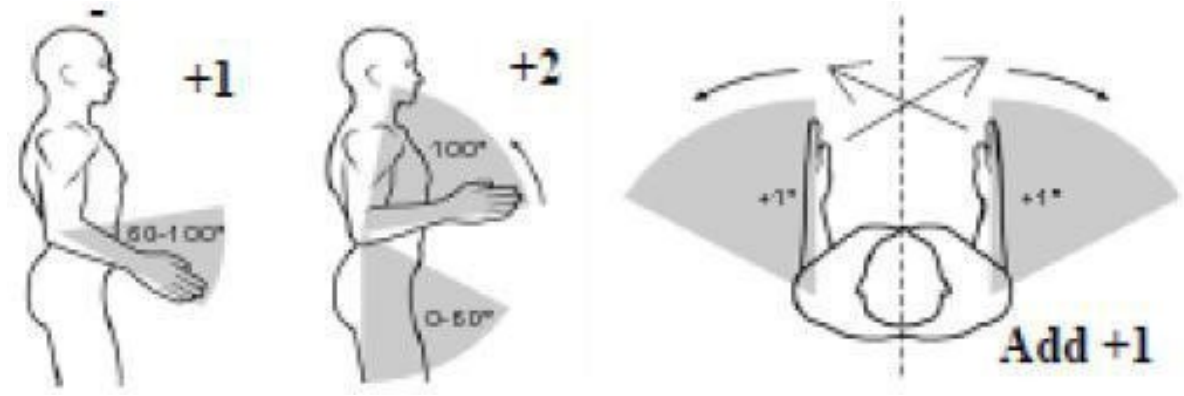

Figure 4. Lower Arm Position

Based on this work posture, the lower arm formed an angle of $90^{\circ}$. With an angle value of $90^{\circ}$, it can be seen the lower arm has a value of +1 . Because in the process of straightening service comply, the arms frequently came out from the sides of the body, the score was then given +1 . Therefore, the total value for the lower arm was $1+1=+2$.

3) Wrist

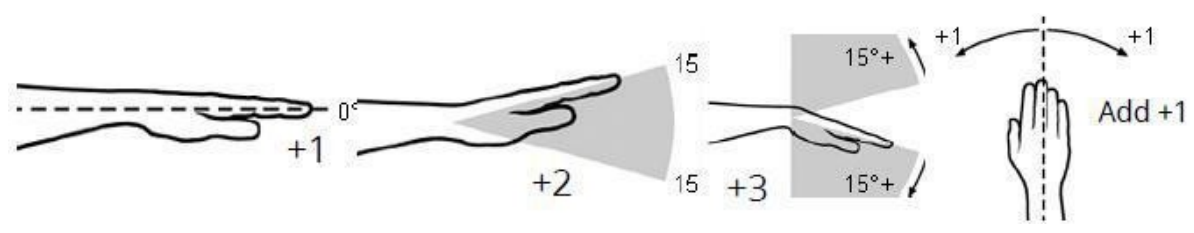

Figure 5. Wrist Position

To determine the wrist posture, there are two things to consider: the angle and rotation of the wrist. Based on this work posture, the wrist angle of $15^{\circ}$ can be determined. With an angle of $15^{\circ}$, a wrist position value of +2 was obtained. The wrists were in both radial and ulnar deviations and were then given a score of +1 . Thus, the value of the position of the wrist was 3 $+1=+4$. After knowing the upper arm, power arm, and wrist posture values, the posture values can be seen in table A. The table A values are obtained by matching the upper arm, power arm, and wrist values with table A. The following is the determination of table A. Thus, it can be seen the value of table A is +4 . There was a muscle use score in doing work of +1 because workers performed movements with the riskiest postures repeatedly over 4 times in 1 minute. Meanwhile, the value for the level of burden of work done was +0 because loading was done only occasionally and the load was less than $2 \mathrm{~kg}$. Thus, the total value of category A work postures was $4+1+0=+5$. This value of +5 was used to find out the value of table $\mathrm{C}$ or the final score at the end of the calculation. The final of wrist score is shown at Table 1 
Table 1. Table A

\begin{tabular}{|c|c|c|c|c|c|c|c|c|c|}
\hline \multirow{2}{*}{\multicolumn{2}{|c|}{ Table A }} & \multicolumn{8}{|c|}{ Wrist Score } \\
\hline & & \multicolumn{2}{|c|}{1} & \multicolumn{2}{|c|}{2} & \multicolumn{2}{|c|}{3} & \multicolumn{2}{|c|}{4} \\
\hline \multirow{3}{*}{$\begin{array}{l}\text { Upper } \\
\text { Arm }\end{array}$} & \multirow{3}{*}{$\begin{array}{c}\text { Lower } \\
\text { Arm }\end{array}$} & \multirow{2}{*}{\multicolumn{2}{|c|}{$\begin{array}{l}\text { Wrist } \\
\text { Twist }\end{array}$}} & \multirow{2}{*}{\multicolumn{2}{|c|}{$\begin{array}{l}\text { Wrist } \\
\text { Twist }\end{array}$}} & \multirow{2}{*}{\multicolumn{2}{|c|}{$\begin{array}{l}\text { Wrist } \\
\text { Twist }\end{array}$}} & \multirow{2}{*}{\multicolumn{2}{|c|}{$\begin{array}{l}\text { Wrist } \\
\text { Twist }\end{array}$}} \\
\hline & & & & & & & & & \\
\hline & & 1 & 2 & 1 & 2 & 1 & 2 & 1 & 2 \\
\hline \multirow[t]{3}{*}{1} & 1 & 1 & 2 & 2 & 2 & $z$ & 3 & 3 & 3 \\
\hline & 2 & 2 & 2 & 2 & 2 & 3 & 3 & 3 & 3 \\
\hline & 3 & 2 & 3 & 3 & 3 & 3 & 3 & 4 & 4 \\
\hline \multirow[t]{6}{*}{2} & 1 & 2 & 3 & 3 & 3 & 3 & 4 & 4 & 4 \\
\hline & 2 & 3 & 3 & 3 & 3 & 3 & 4 & 4 & 4 \\
\hline & 3 & 3 & 4 & 4 & 4 & 4 & 4 & 5 & 5 \\
\hline & 1 & 3 & 3 & 4 & 4 & 4 & 4 & 5 & 5 \\
\hline & 2 & 3 & 4 & 4 & 4 & 4 & 4 & 5 & 5 \\
\hline & 3 & 4 & 4 & 4 & 4 & 4 & 5 & 5 & 5 \\
\hline \multirow[t]{3}{*}{4} & 1 & 4 & 4 & 4 & 4 & 4 & 5 & 5 & 5 \\
\hline & 2 & 4 & 4 & 4 & 4 & 4 & 5 & 5 & 5 \\
\hline & 3 & 4 & 4 & 4 & 5 & 5 & 5 & 6 & 6 \\
\hline \multirow[t]{3}{*}{5} & 1 & 5 & 5 & 5 & 5 & 5 & 6 & 6 & 7 \\
\hline & 2 & 5 & 6 & 6 & 6 & 6 & 7 & 7 & 7 \\
\hline & 3 & 6 & 6 & 6 & 7 & 7 & 7 & 7 & 8 \\
\hline \multirow[t]{3}{*}{6} & 1 & 7 & 7 & 7 & 7 & 7 & 8 & 8 & 9 \\
\hline & 2 & 8 & 8 & 8 & 8 & 8 & 9 & 9 & 9 \\
\hline & 3 & 9 & 9 & 9 & 9 & 9 & 9 & 9 & 9 \\
\hline
\end{tabular}

b. Assessment of work postures for the body included in the category B (Neck, Trunk, and Leg)

1) Neck

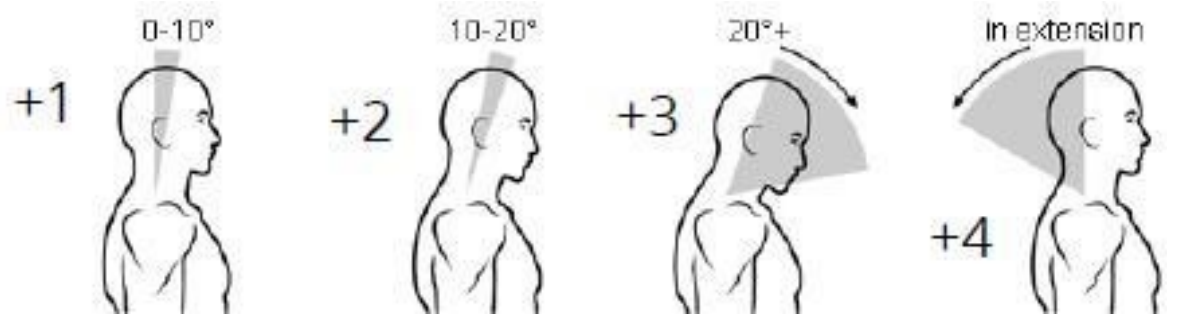

Figure 6. Neck Position

Based on this work posture it can be seen that the position of the neck is bent by $16.80^{\circ}$ with a value of +2 . Thus, the neck position value is +2 .

2) Trunk
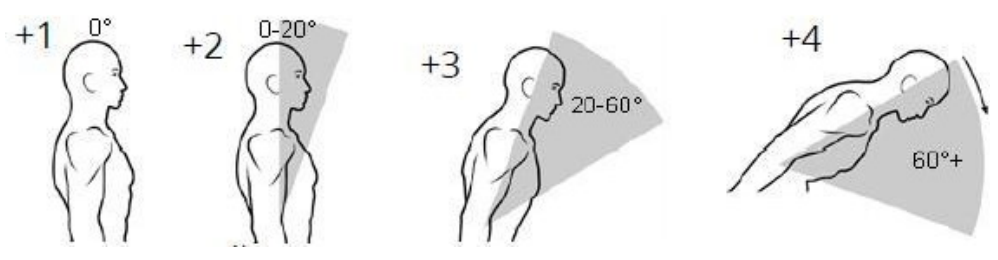

Figure 7. Trunk Position 
Trunk value was obtained from the identification of the angle formed by the back from a vertical axis when workers performed their jobs. Based on this work posture, it is known that the back position formed an angle of $8.85^{\circ}$ to the vertical axis, and therefore it was given a value of +2 . Thu, the value of the back position was +2 .

\section{3) Legs}

The leg posture was determined by looking at the position of the foot whether the foot was supported with weights evenly distributed. In this posture, the legs were supported with weights evenly distributed so that they were given +1 .

After knowing the position of the trunk, neck, and legs, then the next step was to determine the value of the posture for table B. The value of table B was obtained by matching the values of the trunk, neck, and legs into table 2 .

Table 2. Table B

\begin{tabular}{|c|c|c|c|c|c|c|c|c|c|c|c|c|}
\hline \multirow{4}{*}{$\begin{array}{c}\text { Neck } \\
\text { Posture } \\
\text { Score }\end{array}$} & \multicolumn{12}{|c|}{ Table B: Trunk Posture } \\
\hline & 1 & & & & & & 2 & & 5 & & 6 & \\
\hline & Le & & Le & & Le & & Le & & $\mathrm{Le}$ & & Le & \\
\hline & 1 & 2 & 1 & 2 & 1 & 2 & 1 & 2 & & 2 & 1 & 2 \\
\hline 1 & 1 & 3 & 2 & 3 & 3 & 4 & 5 & 5 & 6 & 6 & 7 & 7 \\
\hline 2 & 2 & 3 & 2 & 3 & 4 & 5 & 5 & 5 & 6 & 7 & 7 & 7 \\
\hline 3 & 3 & 3 & 3 & 4 & 4 & 5 & 5 & 6 & 6 & 7 & 7 & 7 \\
\hline 4 & 5 & 5 & 5 & 6 & 6 & 7 & 7 & 7 & 7 & 7 & 8 & 8 \\
\hline 5 & 7 & 7 & 7 & 7 & 7 & 8 & 8 & 8 & 8 & 8 & 8 & 8 \\
\hline 6 & 8 & 8 & 8 & 8 & 8 & 8 & 8 & 9 & 9 & 9 & 9 & 9 \\
\hline
\end{tabular}

Thus, the value of Table B was +2 . Also, the value of muscle use (muscle use score) on the feet of workers was +1 because of the position of foot being stationary was more than 10 minutes. Because no force or load was experienced by the foot, the score was given a value of 0 in force/load. Thus, the total value of category B work postures was $2+1+$ $0=+3$. This value of +3 was used to find out the value of table $\mathrm{C}$ or the final score at the end of the calculation. After obtaining each value in categories $\mathrm{A}$ and $\mathrm{B}$, the value was determined by matching each of the values generated by category A and category B in table C. The total work posture value in category A was +5 and the work posture value in category B was +3 and it is shown at Table 3 .

Table 3. Table C

\begin{tabular}{|c|c|c|c|c|c|c|c|c|}
\hline \multicolumn{2}{|c|}{ Table C } & \multicolumn{6}{|c|}{ Neck, Trunk, Leg Score } \\
\cline { 2 - 9 } \multicolumn{2}{|c|}{} & 1 & 2 & 3 & 4 & 5 & 6 & $7+$ \\
\hline Wrist / & 1 & 1 & 2 & 3 & 3 & 4 & 5 & 5 \\
\cline { 2 - 9 } Arm & 2 & 2 & 2 & 3 & 4 & 4 & 5 & 5 \\
\cline { 2 - 8 } Score & 3 & 3 & 3 & 3 & 4 & 4 & 5 & 6 \\
\cline { 2 - 9 } & 4 & 3 & 3 & 3 & 4 & 5 & 6 & 6 \\
\cline { 2 - 8 } & 5 & 4 & 4 & 4 & 5 & 6 & 7 & 7 \\
\cline { 2 - 8 } & 6 & 4 & 4 & 5 & 6 & 6 & 7 & 7 \\
\cline { 2 - 8 } & 7 & 5 & 5 & 6 & 6 & 7 & 7 & 7 \\
\cline { 2 - 9 } & $8+$ & 5 & 5 & 6 & 7 & 7 & 7 & 7 \\
\hline
\end{tabular}

The value generated from table $\mathrm{C}$ is +4 . This figure is the RULA score used as a basis for consideration in determining the workstation reshuffle. A score of +4 indicated that the workstation needs a change.

\section{Discussion}

Based on the result of RULA assessment about the value of the worker's posture of +4 , this indicated that further investigation needs to be done and perhaps, improvements in the work station design need to be analyzed. Improvements in the design workstation should consider various ways, such as aspects of ergonomics. Some considerations can be used to modify the work place design are:

1. Following the ergonomic checkpoint [18]:

a. The workstation design should adjust the height of table that considers the worker's elbow height

b. The workstation should consider the $5 \%$ percentile in order for accessible and reachable area of tools placed in the workstation

c. Separate the area through colour identification based on the frequency of use for each tool placed

d. Provide foot rest in order to support the body weight of workers on both feet and placing the table close to the body

e. Use adjustable chairs with backrest

2. Considering the score from RULA assessment

Table 4. Segmentation Area to Reduce RULA Score

\begin{tabular}{|c|c|c|c|c|c|c|c|c|}
\hline \multicolumn{2}{|c|}{ Table C } & \multicolumn{9}{|c|}{ Neck, Trunk, Leg Score } \\
\cline { 2 - 9 } \multicolumn{2}{|c|}{} & 1 & 2 & 3 & 4 & 5 & 6 & $7+$ \\
\hline Wrist / & 1 & 1 & 2 & 3 & 3 & 4 & 5 & 5 \\
\cline { 2 - 8 } Arm & 2 & 2 & 2 & 3 & 4 & 4 & 5 & 5 \\
\cline { 2 - 8 } Score & 3 & 3 & 3 & 3 & 4 & 4 & 5 & 6 \\
\cline { 2 - 8 } & 4 & 3 & 3 & 3 & 4 & 5 & 6 & 6 \\
\cline { 2 - 8 } & 5 & 4 & 4 & 4 & 5 & 6 & 7 & 7 \\
\cline { 2 - 8 } & 6 & 4 & 4 & 5 & 6 & 6 & 7 & 7 \\
\cline { 2 - 8 } & 7 & 5 & 5 & 6 & 6 & 7 & 7 & 7 \\
\cline { 2 - 8 } & $8+$ & 5 & 5 & 6 & 7 & 7 & 7 & 7 \\
\hline
\end{tabular}

Based on the table 4, it can be seen that the final RULA score is in the area bordered with the red line. In order to make improvements for work postures, there are some considerations which can be used to reduce the score. We need to improve the design because the RULA score was 4 and close to 5 which need to be changed soon. Some considerations which can be used are:

\section{a. Upper arm}

Because the upper arm score was +3 and there were some indication that the degrees between upper arm and trunk was more than $45^{\circ}$, we can reduce the height of the desk, considering the height of elbow of the operator.

b. Wrist

The Wrist score was +2. In order to reduce the score, we 
can give some wrist support to reduce the load in the carpal tunnel. Therefore, it can reduce the probability the carpal tunnel syndrome.

\section{Conclusion}

Based on the data processing and analyses carried out in this study, there are several conclusions as follows:

1. RULA assessment result stated that working postures in Service Comply showed the value generated from table $\mathrm{C}$ is +4. This means that activities in service compliance have a low risk level

2. Service Comply alignment work requires high accuracy. Therefore, it is necessary to redesign work stations that are more comfortable to reduce injuries that affect the productivity of workers. In designing work station, it is necessary to determine the size of the design components. Based on the principle of fit with ration of machine to man, it means that the size of the machine must adjust the size of the human body, the design size can then be obtained from anthropometric data.

\section{REFERENCES}

[1] Frisby, C. B. "Ergonomics: Fitting The Job To The Worker." Journal of the Royal Society of Arts, vol. 109, no. 5056, 1961, pp. 265-278. JSTOR, www.jstor.org/stable/41366865.

[2] Punnett, L, and Wegman, D.H. Work-Related Musculoskeletal Disorders: The Epidemiologic Evidence and The Debate. Journal of Electromyography and Kinesiology.14: 13-23. Stanton, Neville et al. Handbook of Human Factors and Ergonomics Methods. London: CRC Press. 2005.

[3] Putz-Anderson, Vern., Et al. Musculoskeletal Disorders and Workplace Factors: A Critical Review of Epidemiologic Evidence for Work-Related Musculoskeletal Disorders of the Neck, Upper Extremity, and Low Back. U.S. Department of Health and Human Services. 1997.

[4] Thorp, A.A., Kingwell, B.A., Owen, N., Dunstan, D.W., Breaking up workplace sitting time with intermittent standing bouts improves fatigue and musculoskeletal discomfort in overweight/obese office workers. Occup. Environ. Med. 71 (11), 765-771. 2014.

[5] Ding, D., Lawson, K.D., Kolbe-Alexander, T.L., Finkelstein, E.A., Katzmarzyk, P.T., van Mechelen, W., Lancet Physical Activity Series 2 Executive Committee, The economic burden of physical inactivity: a global analysis of major non-communicable diseases. Lancet 388 (10051), 1311-1324. 2016.

[6] Karakolis, T., Barrett, J., Callaghan, J.P., A comparison of trunk biomechanics, musculoskeletal discomfort and productivity during simulated sit-stand office work. Ergonomics 59 (10), 1275-1287. 2016.

[7] Sutalaksana, Iftikar Z. Technical Procedures for Working. Bandung Institute of Technology. MTI-ITB. 1979.
[8] Pangaribuan, D. M. Work Posture Analysis with RULA Method on the Employees of the USU Library Services Division in Medan, Final Project of the USU Industrial Engineering Department, Medan. 2009.

[9] Roman-Liu, D., Comparison of concepts in easy-to-use methods for MSD risk assessment. Applied ergonomics 45, 420-427. 2014.

[10] Setyanto NW, Efranto RY, Lukodono RP, Dirawidya A. Ergonomics analysis in the scarfing process by OWAS, NIOSH and Nordic Body Map's method at slab steel plant's division. IJIRSET 2015; 4(3): 1086-93

[11] Lukodono, Rio Prasetyo; Ulfa, Siti Kholisotul. Perbaikan Fasilitas Pemindahan Bag Pakan Udang Di Departemen Packaging Guna Mengurangi Resiko Cedera Tulang Belakang. Journal of Engineering and Management in Industrial System, v. 4, n. 1, p. p31-39, dec. 2016.

[12] Manghisi, V.M., et al., Real time RULA assessment using Kinect v2 sensor, Applied Ergonomics. 2017 http:// Zdx.doi.org/10.1016/j.apergo.2017.02.015

[13] Chen, Janice D., Falkmer, Torbjör, Parsons, Richard, Buzzar , Jennifer, Ciccarelli , Marina, Impact of experience when using the Rapid Upper Limb Assessment to assess postural risk in children using information and communication technologies, Applied Ergonomics 45. 2014 398e405

[14] Dockrell, S., O'Grady, E., Bennett, K., Mullarkey, C., Mc Connell, R., Ruddy, R., Twomey, S., Flannery, C. An investigation of the reliability of Rapid Upper Limb Assessment (RULA) as a method of assessment of children's computing posture. Appl. Ergon. 43, 632-636. .2012

[15] Wilson, J.R dan Corlett E.N. Evaluation of Human Work : A Practical Ergonomics Methodology. Taylor and Franchis Ltd, London. 1995.

[16] McAtamney, Lynn, and E Nigel. Corlett. RULA: A survey method for the investigation of workrelated upper limb disorder. Applied ergonomic vol 24. 1993

[17] Stanton, Neville, et al. Handbook of Human Factors and Ergonomic Methods. USA:CRC: Press. 2005

[18] International Labour Office. "Ergonomic Checkpoints Practical and Easy to Implement Solutions for Improving Safety, Health and Working Conditions”. International Labour Office: Geneva. 2010. 